\title{
Trust, Social and Personal Attitudes after Wildfires in a Rural Region of Greece
}

\author{
Vicky Papanikolaou ${ }^{1 *}$, Dimitrios Adamis ${ }^{2,3}$, Robert C. Mellon ${ }^{4}$, \\ Gerasimos Prodromitis ${ }^{4}$, John Kyriopoulos ${ }^{1}$ \\ ${ }^{1}$ Department of Health Service Management, National School of Public Health, Athens, Greece \\ ${ }^{2}$ Research and Academic Institute of Athens, Athens, Greece \\ ${ }^{3}$ Institute of Psychiatry, Kings College, London, UK \\ ${ }^{4}$ Department of Psychology, Panteion University of Social and Political Sciences, Athens, Greece \\ Email: \{"bpapanikolaou, jkyriopoulos\}@esdy.edu.gr, vpapan@hol.gr, dimaadamis@yahoo.com,
} \{Melon, Prod\}@panteion.gr

Received August 12 ${ }^{\text {th }}, 2011$; revised October $1^{\text {st }}, 2011$; accepted November $2^{\text {nd }}, 2011$

\begin{abstract}
We investigated the trust in institutions, social values and personal attitudes of individuals in a part of Greece, after a wildfire disaster. The design of the study was a cross sectional, case-control study. Data collected were trust in institutions, social and personal attitudes, type and number of losses. The results show that victims and controls have low trust in all the institutions and share similar social and personal attitudes. Controlling for other variables, victims of the wildfires were less likely to appreciate stable social rules, to value the dialogue, autonomy, mutual support, modesty, wealth, equality, compliance with law, devotion, public recognition, safety and less likely to trust the government but more likely to trust church. This study suggests that victims of the wildfires in Greece did not appreciate important social values which bring a society together, they have a low trust in institutions, and they have a weak social cohesion which perhaps pre-existed the disaster; just the disaster has made all of them worse.
\end{abstract}

Keywords: Disasters; Wildfires; Greece; Trust; Social Capital; Social Cohesion

\section{Introduction}

Disaster involves not only physical and psychological destruction but also social destruction. At the onset of a natural disaster social theories have emphasized that the disaster can potential bring people together to respond to common threat (Turner, 1978).

However after a disaster the loss of important support is inevitable and social and community resources are weakening exactly the time when victims need them (Kaniasty \& Norris, 1993). The consequences are changes in the social system which is the most common characteristic after a disaster. (Crocq, Doutheau, \& Salham, 1987). Because of that most of the definitions of a disaster follows a sociological point of view in their description (Lopez-Ibor, 2006). Furthermore, it has been recognized that mental health outcomes are not only dependent on the individual traumatic experiences and the losses, but also from the destruction of the social context which happens after a disaster (Kawachi \& Subramanian, 2006; Galea, Tracy, Norris, \& Coffey, 2008).

Although a number of papers have investigated social construction, norms, trust, networking and social support in the preparedness of a disaster in theoretical and in research levels e.g. (Agrawal et al., 2008; Barton, 1969; Dynes \& Quarantelli, 1980; Jalali, 2002; Miller, 2007; Schellong, 2007) the social responses have been less studied in the aftermath of a disaster (Evans \& Rollins, 2008). Similarly the nature of a disaster may affect in different ways the social dynamics and also the different cultures and social-psychological factors, may affect also

*Corresponding author. the responses to a disaster (Evans \& Rollins, 2008). Furthermore, Carroll, Higgins, Cohn, \& Burchfield (2006) examined the specific sources of social conflict in communities during and after wildfire in the American West. They found that conflict occurs when social relations are disembedded by non-local agency, and there was an apparent loss of local involvement. When forms of interaction and problem solving imposed by outside organizations during and after wildfire events they often were resisted by local agencies which were also difficult to act because of local capacity limitations.

Moreover, trust is a sign of cooperative behavior: A high level of trust facilitates cooperative behavior of a victim with those who can help outside; opposite, a low level of trust inhibits cooperation and thus potentially can reduce the outside support (Montgomery, Jordens, \& Little, 2008). Similarly social and personal attitudes are surrogate markers of social foundations and can facilitate or block support after a disaster.

Natural disasters are frequent events in Greece and wildfire disasters are more frequent (EM-DAT 2008). In August of 2007 an intense and destructive wildfire broke out in the Peloponnesus peninsula in Greece. The fires were uncontrollable for several days and it was estimated that about 1500 square kilometers of forests, olive trees, and farmland were destroyed. Also villages were burned in these fires and sixty people were killed (EM-DAT 2008). A national disaster was declared and the areas affected by the fires were designated for further support. Mental health teams were called to support the suffering population aiming to restore psychological and social functioning of individuals but also of fire-fighters. Similarly, research was undertaken to measure mental health and social problems for an 
effective public planning for disasters.

The aims of the present study were to investigate the impact of wildfires in the affected communities in terms of trust in certain institution/organizations and their social values and personal attitudes.

\section{Method}

\section{Design of the Study}

Cross sectional case control study.

\section{Participants}

The cases were residents aged from 18 years to 65 years old who lived in the disaster areas. The controls were closely matched for gender, age, educational, marital and regional distributions and were residents of directly adjoining areas in which there was no fire damage in the immediate neighborhood. A more detailed description of the method has been published elsewhere (Mellon, Papanikolau, \& Prodromitis, 2009).

\section{Measurements}

1) Demographic characteristics (age, gender, educational background, marital status, occupation).

2) Symptom Checklist 90-Revised (SCL-90-R; Derogatis, 1992). The SCL-90-R has 90 items, which measure the degree of distress experienced the individual during the last 7 days, using a 5-point scale ( 0 to 4 ) that ranges from "not at all" to "extremely". The SCL-90-R can be scored for nine symptom dimensions. In addition to the nine dimentions, there are three global indices that are computed. The Global Severity Index (GSI), which is the sum of all the nonzero responses, divided by 90 (if there are no missing responses) and reflects both the number of symptoms endorsed and the intensity of perceived distress. The Positive Symptom Total (PST) which is defined as the number of symptoms to which the patient indicates a nonzero response. This is a measure of the number of symptoms endorsed. Thus it can be interpreted as a measurement of symptoms span. The Positive Symptom Distress Index (PSDI) is calculated by dividing the sum of all item values by the PST; thus, this is a measure of "intensity" corrected for the number of symptoms. The validity and reliability of the Greek SCL-90$\mathrm{R}$ has proven to be satisfactory (Donias, Karastergiou, \& Manos, 1991).

3) Number and type of losses as a result of the fire including: a) damage to property (Yes vs No); b) complete damage and loss of property (Yes vs No); c) personal injury or injury of a close family member (Yes vs No); and d) deaths of close family members. (Yes vs No). The responses to questions a and b were mutually exclusive. If more than one loss had happened all of them counted (number of losses).

4) A questionnaire which examines the trust of respondents in 12 institutions/establishments/organizations namely: Government, Church, Military, Local government, Private sector, Trade-unions, Non Governmental/Voluntary organizations, Justice, Education, Police, Political parties, Media and None of the above.

5) A questionnaire with 21 social values in which the participants could choose the ones which were more representative of them. Among the social values were Prestige, Devotion, Autonomy, Display of power, Mutual Help, Modesty, Wealth,
Equality, Tradition, Public recognition, Safety, and others (for a full list see Table 3).

\section{Procedure}

Data were collected in face-to-face interviews conducted during a 14-day period beginning 6 months after the outbreak of the wildfires (March 2008). Households in designated disaster areas and in directly adjoining areas undamaged by fire were selected randomly from residency data provided by the municipalities surveyed. In each household only one interview was conducted.

\section{Ethics}

The study has been approved by the Ministry of Health and informed consent was obtained from each participant.

\section{Statistical Analysis}

Data were analyzed with PASW (SPSS) v18, using appropriate bivariate statistics. For the non-normally distributed data, non-parametric tests were used. The Q Local v 2.1.11, was used for the estimation of the standardized $\mathrm{T}$ scores from the raw data for the SCL-90-R scale.

\section{Results}

\section{Demographics}

The initial sample consisted of 800 participants: 409 cases (those victims from the disaster) and 391 controls. The two groups did not differ between them in demographic and occupational characteristics, but a higher proportion of those in control group had higher education compared to cases, while those who finished primary or secondary school had similar representativeness in the two groups (see Table 1).

\section{Trust in Institutions}

We compared the trust of cases and controls in 12 different institutions/organizations (Table 2). Both groups (victims of the disaster and controls) had a low trust in all the institutions for which they asked (see also Table 2 column "Total”). In the highest rate was Church but only 1 out of 3 participants had a trust in the Church. All the other institutions had a low preference of trust. Similarly about 35 of the participants did not trust any institution. As this percentage was high for both groups, we investigate this population further (see below). In addition, there were not statistically significant differences between cases (victims) and controls in their trust in the investigated organizations with only one exception the trust in government. More victims did not have any trust to government compared to the controls.

\section{Social Values and Personal Attitudes}

The most important social and personal values for the entire sample were dialogue and communication among people, mutual support, nature, safety and creativity, while the less important were Ostentation of power/wealth, Adventure, Variety, Wealth, and Prestige (see Table 3 column "Total”).

For the victims nature was a significant value compared to controls. 
Table 1.

Demographic characteristics of sample.

\begin{tabular}{|c|c|c|c|c|c|c|}
\hline & & \multicolumn{2}{|c|}{ Cases $(\mathrm{N}=409)$} & \multicolumn{2}{|c|}{ Controls (N = 391) } & \multirow[t]{2}{*}{ Pearson $x^{2}$} \\
\hline & & Count & Column N\% & Count & Column N\% & \\
\hline \multirow{2}{*}{ Gender } & Male & 215 & $52.6 \%$ & 202 & $51.7 \%$ & \multirow{2}{*}{$\mathrm{x}^{2}=.07, \mathrm{df} 1, \mathrm{p}=.8(\mathrm{NS})$} \\
\hline & Female & 194 & $47.4 \%$ & 189 & $48.3 \%$ & \\
\hline \multirow{5}{*}{ Age group } & $18-25$ & 74 & $18.1 \%$ & 67 & $17.1 \%$ & \multirow{5}{*}{$\mathrm{x}^{2}=.93, \mathrm{df} 4, \mathrm{p}=.9(\mathrm{NS})$} \\
\hline & $26-35$ & 100 & $24.4 \%$ & 102 & $26.1 \%$ & \\
\hline & $36-45$ & 86 & $21.0 \%$ & 88 & $22.5 \%$ & \\
\hline & $46-55$ & 80 & $19.6 \%$ & 75 & $19.2 \%$ & \\
\hline & $56-65$ & 69 & $16.9 \%$ & 59 & $15.1 \%$ & \\
\hline \multirow{3}{*}{ Education } & Primary school & 106 & $25.9 \%$ & 91 & $23.3 \%$ & \multirow{3}{*}{$\mathrm{x}^{2}=7.16$, df $2, \mathrm{p}=.03$} \\
\hline & Secondary school & 272 & $66.5 \%$ & 248 & $63.4 \%$ & \\
\hline & College/university & 31 & $7.6 \%$ & 52 & $13.3 \%$ & \\
\hline \multirow{4}{*}{ Marital status } & Married & 268 & $65.5 \%$ & 251 & $64.2 \%$ & \multirow{4}{*}{$\mathrm{x}^{2}=.48, \mathrm{df} 3, \mathrm{p}=.92(\mathrm{NS})$} \\
\hline & Single & 127 & $31.1 \%$ & 127 & $32.5 \%$ & \\
\hline & Divorced & 4 & $1.0 \%$ & 5 & $1.3 \%$ & \\
\hline & Widowed & 10 & $2.4 \%$ & 8 & $2.0 \%$ & \\
\hline \multirow{3}{*}{ Occupation } & Professional occupation & 79 & $19.3 \%$ & 70 & $17.9 \%$ & \multirow{3}{*}{$\mathrm{x}^{2}=3.4, \mathrm{df} 2, \mathrm{p}=.18(\mathrm{NS})$} \\
\hline & Sales and customer service occupation & 67 & $16.4 \%$ & 84 & $21.5 \%$ & \\
\hline & Elementary occupation & 263 & $64.3 \%$ & 237 & $60.6 \%$ & \\
\hline
\end{tabular}

Table 2.

Trust of victims and controls in institutions, establishments, organizations.

\begin{tabular}{|c|c|c|c|c|c|c|c|c|}
\hline \multirow{2}{*}{\multicolumn{2}{|c|}{ Institutions/Organizations }} & \multicolumn{2}{|c|}{ Cases $(\mathrm{N}=409)$} & \multicolumn{2}{|c|}{ Controls (N = 391) } & \multicolumn{2}{|c|}{ Total } & \multirow{2}{*}{ Pearson $x^{2}$} \\
\hline & & Count & Column N \% & Count & Column N \% & Count & Column N \% & \\
\hline \multirow{2}{*}{ Government } & NO & 362 & $88.5 \%$ & 324 & $82.9 \%$ & 686 & $85.8 \%$ & \multirow{2}{*}{$x^{2}=5.21$, df $1, \mathbf{p}=\mathbf{0 . 0 2}$} \\
\hline & YES & 47 & $11.5 \%$ & 67 & $17.1 \%$ & 114 & $14.3 \%$ & \\
\hline \multirow{2}{*}{ Church } & NO & 268 & $65.5 \%$ & 276 & $70.6 \%$ & 544 & $68.0 \%$ & \multirow{2}{*}{$\mathrm{x}^{2}=2.35, \mathrm{df} 1, \mathrm{p}=.12(\mathrm{NS})$} \\
\hline & YES & 141 & $34.5 \%$ & 115 & $29.4 \%$ & 256 & $32.0 \%$ & \\
\hline \multirow{2}{*}{ Military } & NO & 377 & $92.2 \%$ & 360 & $92.1 \%$ & 737 & $92.1 \%$ & \multirow{2}{*}{$\mathrm{x}^{2}=.003, \mathrm{df} 1, \mathrm{p}=.96(\mathrm{NS})$} \\
\hline & YES & 32 & $7.8 \%$ & 31 & $7.9 \%$ & 63 & $7.9 \%$ & \\
\hline \multirow{2}{*}{ Local government } & NO & 393 & $96.1 \%$ & 381 & $97.4 \%$ & 774 & $96.8 \%$ & \multirow{2}{*}{$\mathrm{x}^{2}=1.16, \mathrm{df} 1, \mathrm{p}=.28(\mathrm{NS})$} \\
\hline & YES & 16 & $3.9 \%$ & 10 & $2.6 \%$ & 26 & $3.3 \%$ & \\
\hline \multirow{2}{*}{ Private sector } & NO & 390 & $95.4 \%$ & 366 & $93.6 \%$ & 756 & $94.5 \%$ & \multirow{2}{*}{$\mathrm{x}^{2}=1.18, \mathrm{df} 1, \mathrm{p}=.28(\mathrm{NS})$} \\
\hline & YES & 19 & $4.6 \%$ & 25 & $6.4 \%$ & 44 & $5.5 \%$ & \\
\hline \multirow{2}{*}{ Trade unions } & NO & 394 & $96.3 \%$ & 369 & $94.4 \%$ & 763 & $95.4 \%$ & \multirow{2}{*}{$\mathrm{x}^{2}=1.74, \mathrm{df} 1, \mathrm{p}=.19(\mathrm{NS})$} \\
\hline & YES & 15 & $3.7 \%$ & 22 & $5.6 \%$ & 37 & $4.6 \%$ & \\
\hline \multirow{2}{*}{ Voluntary/no governmental } & NO & 365 & $89.2 \%$ & 348 & $89.0 \%$ & 713 & $89.1 \%$ & \multirow{2}{*}{$\mathrm{x}^{2}=.012, \mathrm{df} 1, \mathrm{p}=.91(\mathrm{NS})$} \\
\hline & YES & 44 & $10.8 \%$ & 43 & $11.0 \%$ & 87 & $10.9 \%$ & \\
\hline \multirow{2}{*}{ Justice } & NO & 381 & $93.2 \%$ & 356 & $91.0 \%$ & 737 & $92.1 \%$ & \multirow{2}{*}{$\mathrm{x}^{2}=1.22$, df $1, \mathrm{p}=.27(\mathrm{NS})$} \\
\hline & YES & 28 & $6.8 \%$ & 35 & $9.0 \%$ & 63 & $7.9 \%$ & \\
\hline \multirow{2}{*}{ Education } & NO & 387 & $94.6 \%$ & 368 & $94.1 \%$ & 755 & $94.4 \%$ & \multirow{2}{*}{$\mathrm{x}^{2}=.095, \mathrm{df} 1, \mathrm{p}=.76(\mathrm{NS})$} \\
\hline & YES & 22 & $5.4 \%$ & 23 & $5.9 \%$ & 45 & $5.6 \%$ & \\
\hline \multirow{2}{*}{ Police } & NO & 370 & $90.5 \%$ & 368 & $94.1 \%$ & 738 & $92.3 \%$ & \multirow{2}{*}{$\mathrm{x}^{2}=3.73$, df $1, \mathrm{p}=.052(\mathrm{NS})$} \\
\hline & YES & 39 & $9.5 \%$ & 23 & $5.9 \%$ & 62 & $7.8 \%$ & \\
\hline \multirow{2}{*}{ Political parties } & NO & 408 & $99.8 \%$ & 390 & $99.7 \%$ & 798 & $99.8 \%$ & \multirow{2}{*}{$\mathrm{x}^{2}=.001 . \mathrm{df} 1, \mathrm{p}=.97(\mathrm{NS})$} \\
\hline & YES & 1 & $.2 \%$ & 1 & $.3 \%$ & 2 & $.3 \%$ & \\
\hline \multirow{2}{*}{ Media } & NO & 378 & $92.4 \%$ & 363 & $92.8 \%$ & 741 & $92.6 \%$ & \multirow{2}{*}{$\mathrm{x}^{2}=.05, \mathrm{df} 1, \mathrm{p}=.82(\mathrm{NS})$} \\
\hline & YES & 31 & $7.6 \%$ & 28 & $7.2 \%$ & 59 & $7.4 \%$ & \\
\hline \multirow{2}{*}{ None of the above } & NO & 267 & $65.3 \%$ & 248 & $63.4 \%$ & 515 & $64.4 \%$ & \multirow{2}{*}{$\mathrm{x}^{2}=.3, \mathrm{df} 1, \mathrm{p}=.58(\mathrm{NS})$} \\
\hline & YES & 142 & $34.7 \%$ & 143 & $36.6 \%$ & 285 & $35.6 \%$ & \\
\hline
\end{tabular}


Table 3.

Social and personal attitudes of victims and controls.

\begin{tabular}{|c|c|c|c|c|c|c|c|c|}
\hline \multirow{2}{*}{ Values/attitudes } & & \multicolumn{2}{|c|}{ Cases $(\mathrm{N}=409)$} & \multicolumn{2}{|c|}{ Controls $(\mathrm{N}=391)$} & \multicolumn{2}{|c|}{ Total } & \multirow{2}{*}{ Pearson $x^{2}$} \\
\hline & & Count & Column N \% & Count & Column N \% & Count & Column N \% & \\
\hline \multirow{2}{*}{$\begin{array}{l}\text { Dialogue/communication } \\
\text { among people }\end{array}$} & NO & 191 & $46.7 \%$ & 172 & $44.0 \%$ & 363 & $45.4 \%$ & \multirow{2}{*}{$\mathrm{x}^{2}=.59, \mathrm{df}: 1, \mathrm{p}=.442(\mathrm{NS})$} \\
\hline & YES & 218 & $53.3 \%$ & 219 & $56.0 \%$ & 437 & $54.6 \%$ & \\
\hline \multirow{2}{*}{ Stable social rules } & NO & 371 & $90.7 \%$ & 348 & $89.0 \%$ & 719 & $89.9 \%$ & \multirow{2}{*}{$\mathrm{x}^{2}=.64, \mathrm{df}: 1, \mathrm{p}=.424(\mathrm{NS})$} \\
\hline & YES & 38 & $9.3 \%$ & 43 & $11.0 \%$ & 81 & $10.1 \%$ & \\
\hline \multirow{2}{*}{ Ostentation of power/wealth } & NO & 404 & $98.8 \%$ & 385 & $98.5 \%$ & 789 & $98.6 \%$ & \multirow{2}{*}{$\mathrm{x}^{2}=.14, \mathrm{df}: 1, \mathrm{p}=.705(\mathrm{NS})$} \\
\hline & YES & 5 & $1.2 \%$ & 6 & $1.5 \%$ & 11 & $1.4 \%$ & \\
\hline \multirow{2}{*}{ Autonomy } & NO & 312 & $76.3 \%$ & 276 & $70.6 \%$ & 588 & $73.5 \%$ & \multirow{2}{*}{$\mathrm{x}^{2}=3.33, \mathrm{df}: 1, \mathrm{p}=.068(\mathrm{NS})$} \\
\hline & YES & 97 & $23.7 \%$ & 115 & $29.4 \%$ & 212 & $26.5 \%$ & \\
\hline \multirow{2}{*}{ Mutual support } & NO & 211 & $51.6 \%$ & 198 & $50.6 \%$ & 409 & $51.1 \%$ & \multirow{2}{*}{$\mathrm{x}^{2}=.07, \mathrm{df}: 1, \mathrm{p}=.788$ (NS) } \\
\hline & YES & 198 & $48.4 \%$ & 193 & $49.4 \%$ & 391 & $48.9 \%$ & \\
\hline \multirow{2}{*}{ Modesty } & NO & 338 & $82.6 \%$ & 298 & $76.2 \%$ & 636 & $79.5 \%$ & \multirow{2}{*}{$x^{2}=5.06, d f: 1, p=.024$} \\
\hline & YES & 71 & $17.4 \%$ & 93 & $23.8 \%$ & 164 & $20.5 \%$ & \\
\hline \multirow{2}{*}{ Wealth } & NO & 390 & $95.4 \%$ & 363 & $92.8 \%$ & 753 & $94.1 \%$ & \multirow{2}{*}{$\mathrm{x}^{2}=2.29, \mathrm{df}: 1, \mathrm{p}=.130$ (NS) } \\
\hline & YES & 19 & $4.6 \%$ & 28 & $7.2 \%$ & 47 & $5.9 \%$ & \\
\hline \multirow{2}{*}{ Variety } & NO & 399 & $97.6 \%$ & 379 & $96.9 \%$ & 778 & $97.3 \%$ & \multirow{2}{*}{$\mathrm{x}^{2}=.29, \mathrm{df}: 1, \mathrm{p}=.590(\mathrm{NS})$} \\
\hline & YES & 10 & $2.4 \%$ & 12 & $3.1 \%$ & 22 & $2.8 \%$ & \\
\hline \multirow{2}{*}{ Equality } & NO & 314 & $76.8 \%$ & 289 & $73.9 \%$ & 603 & $75.4 \%$ & \multirow{2}{*}{$\mathrm{x}^{2}=.88, \mathrm{df}: 1, \mathrm{p}=.348(\mathrm{NS})$} \\
\hline & YES & 95 & $23.2 \%$ & 102 & $26.1 \%$ & 197 & $24.6 \%$ & \\
\hline Compliance with law & NO & 363 & $88.8 \%$ & 320 & $81.8 \%$ & 683 & $85.4 \%$ & $x^{2}=765 d f \cdot 1-n=006$ \\
\hline Sompondince Wint law & YES & 46 & $11.2 \%$ & 71 & $18.2 \%$ & 117 & $14.6 \%$ & x - 1.05, , $1.1, \mathbf{p}-.000$ \\
\hline Adventure & NO & 401 & $98.0 \%$ & 379 & $96.9 \%$ & 780 & $97.5 \%$ & $x^{2}=102 d f \cdot 1 n=313(N S)$ \\
\hline Aaventure & YES & 8 & $2.0 \%$ & 12 & $3.1 \%$ & 20 & $2.5 \%$ & $\mathrm{x}=1.02, \mathrm{dI} .1, \mathrm{p}=.313$ (IN) \\
\hline Leisure & NO & 300 & $73.3 \%$ & 298 & $76.2 \%$ & 598 & $74.8 \%$ & $x^{2}=87 d f \cdot 1$ \\
\hline Leisure & YES & 109 & $26.7 \%$ & 93 & $23.8 \%$ & 202 & $25.3 \%$ & $\mathrm{X}-.8 /, \mathrm{dr} .1, \mathrm{p}-.351$ (NS) \\
\hline Nature & NO & 203 & $49.6 \%$ & 225 & $57.5 \%$ & 428 & $53.5 \%$ & $x^{2}=503 d f \cdot 1$ \\
\hline Nature & YES & 206 & $50.4 \%$ & 166 & $42.5 \%$ & 372 & $46.5 \%$ & $x=5.03$, ar: $1, \mathbf{p}=.025$ \\
\hline Droctior & NO & 383 & $93.6 \%$ & 368 & $94.1 \%$ & 751 & $93.9 \%$ & $x^{2}=$ \\
\hline Presuge & YES & 26 & $6.4 \%$ & 23 & $5.9 \%$ & 49 & $6.1 \%$ & $.80(\mathrm{NS})$ \\
\hline Crontivity & NO & 303 & $74.1 \%$ & 271 & $69.3 \%$ & 574 & $71.8 \%$ & $y^{2}+{ }^{2}+{ }^{2}$ \\
\hline Creduivity & YES & 106 & $25.9 \%$ & 120 & $30.7 \%$ & 226 & $28.3 \%$ & $2.25, \mathrm{d1} .1, \mathrm{p}-.134$ (IN) \\
\hline Devotion & NO & 371 & $90.7 \%$ & 337 & $86.2 \%$ & 708 & $88.5 \%$ & $x^{2}-1+2+2$ \\
\hline Devotion & YES & 38 & $9.3 \%$ & 54 & $13.8 \%$ & 92 & $11.5 \%$ & $x-4.01$, uг.1, $\mathbf{p}-.043$ \\
\hline Public recognition & NO & 382 & $93.4 \%$ & 328 & $83.9 \%$ & 710 & $88.8 \%$ & $x^{2}=18.11, d f: 1, p=.0001$ \\
\hline & YES & 27 & $6.6 \%$ & 63 & $16.1 \%$ & 90 & $11.3 \%$ & \\
\hline Safety & NO & 256 & $62.6 \%$ & 236 & $60.4 \%$ & 492 & $61.5 \%$ & $42 \mathrm{df} \cdot 1 \mathrm{D}=516(\mathrm{NS})$ \\
\hline Sarety & YES & 153 & $37.4 \%$ & 155 & $39.6 \%$ & 308 & $38.5 \%$ & $x-.42$, U1. $1, \mathrm{p}-.010(10)$ \\
\hline Having a good time & NO & 347 & $84.8 \%$ & 333 & $85.2 \%$ & 680 & $85.0 \%$ & $2=02 \mathrm{df} \cdot 1 \cdot \mathrm{D}=898(\mathrm{NS})$ \\
\hline & YES & 62 & $15.2 \%$ & 58 & $14.8 \%$ & 120 & $15.0 \%$ & .02 , ul.1, $\mathrm{p}-.050$ (1V) \\
\hline Tradition & NO & 312 & $76.3 \%$ & 316 & $80.8 \%$ & 628 & $78.5 \%$ & $=119$ (NS) \\
\hline 119uintivin & YES & 97 & $23.7 \%$ & 75 & $19.2 \%$ & 172 & $21.5 \%$ & $. .44, \mathrm{Ul} .1, \mathrm{p}-.11 \mathrm{~J}$ (IV) \\
\hline State & NO & 371 & $90.7 \%$ & 369 & $94.4 \%$ & 740 & $92.5 \%$ & $\mathrm{x}^{2}=3.87, \mathrm{df} \cdot 1, \mathbf{p}=\mathbf{0 4 9}$ \\
\hline & YES & 38 & $9.3 \%$ & 22 & $5.6 \%$ & 60 & $7.5 \%$ & $x-3.0 /$, ,1. $1, \mathbf{p}-.04 \mathbf{9}$ \\
\hline
\end{tabular}

Other statistically significant differences (Table 3) between cases and controls in their consideration of important social and personal values were: modesty which more controls rated it as important compared to cases, devotion, compliance with law, and public recognition. Opposite more of the victims think that the state is an important value in the society, compared to con- 
trols, but this difference was in close proximity to be statistically significant $(\mathrm{p}=.049)$.

\section{Regression Analysis}

To investigate further the differences of the two groups in both social attitudes and trust after adjusting for other variables, a logistic regression analysis was performed. Dependent variable was the binary variable cases or controls (victim or not by the wildfire), and independent variables were the demographic and individual characteristics (gender, age group, marital status, occupation), the number and type of losses as a result of the fire, the trust in the 12 institutions and the 21 investigated social and personal values. The backward stepwise (likelihood ratio) method was used. The final more parsimonious model is presented in Table 4. Note that some variables although not significant they have effects in the final model and they increase the classification rate. The model classified overall $63 \%$ of cases and controls correctly while for the cases only, it has a correct classification of $70 \%$.

According to Table 4, victims of the wildfires were less likely to value the dialogue and communication, less likely to want stable social rules (but both not in statistically significant level), less likely to value autonomy, mutual support, modesty, wealth equality, compliance with law, adventure, creativity, devotion, public recognition, safety and less likely to trust the government but more likely to trust church.

\section{Further Analysis of Those Who Did Not Trust Any Institution}

As there was a reasonable high number of those who did not trust any institution ( $\mathrm{N}=285,35.6 \%$ ) of the entire sample, we further investigate them to see their psychological profile and their attitudes adjusting for demographic and other characteristics. For this reason a logistic regression analysis was carried out. In this analysis dependent variable was the trust on none institution (outcome yes, no) and independent variables were demographic characteristics, the belonging in the victims or not group, the nine dimensions of psychological symptoms as they measure with the SCL-90R plus the 3 indices of SCL-90R (GSI, PST, PSDI) and the variables of social values and personal attitudes.

The backward stepwise (likelihood ratio) method was used. The final more parsimonious model is presented in Table $\mathbf{5}$. The total sample analyzed here was 606 subjects (mainly missing data in SCL-90R and false positives or negatives in SCL90R which were excluded). The number of participants who did not trust any of the listed institutions was 181 (30\%) and those who trust any was 425 (70\%).

It seems from the Table 5 that those who did not trust any institution were more likely to be the victims of the disaster (cases) with more losses from the disaster, with increased the dimension of depression and paranoia (the later did not reach statistical significant level), with fewer numbers of other psychological symptoms and intensity and they were more likely to value the compliance with law and the state, and less likely to value the leisure.

\section{Discussion}

The results show that the victims of the disaster did not trust to government compared to the controls. Although bivariate statistics shows that this was a significant difference, it's statistically significance disappeared in the regression analysis but the importance of the variable is emerge through its contribution to the final model. The lack of trust in the government has also been reported in other studies which investigated victims of disasters (Quinn 2006).

The surprising result is that both cases and controls have a low trust in nearly all the organizations. Even the Church which is a very powerful institution in Greece and it involves not only in religious maters but also in any aspect of civilian life and politics had a low rate of trust (but the highest among the insti-

Table 4.

Regression analysis: of cases and controls in relation to trust and social and personal attitudes.

\begin{tabular}{|c|c|c|c|c|c|c|c|c|}
\hline \multirow{2}{*}{ Variables $^{1}$} & \multirow{2}{*}{ B } & \multirow{2}{*}{ S.E. } & \multirow{2}{*}{ Wald } & \multirow{2}{*}{$\mathrm{df}$} & \multirow{2}{*}{ Sig. } & \multirow{2}{*}{ Exp (B) } & \multicolumn{2}{|c|}{ 95\% C.I. for $\operatorname{Exp}(B)$} \\
\hline & & & & & & & Lower & Upper \\
\hline Dialogue among people & .304 & .156 & 3.811 & 1 & .051 & 1.355 & .999 & 1.838 \\
\hline Stable social rules & .437 & .252 & 3.007 & 1 & .083 & 1.548 & .945 & 2.536 \\
\hline Autonomy & .427 & .173 & 6.095 & 1 & .014 & 1.532 & 1.092 & 2.150 \\
\hline Mutual support & .311 & .156 & 3.948 & 1 & .047 & 1.365 & 1.004 & 1.854 \\
\hline Modesty & .503 & .191 & 6.951 & 1 & .008 & 1.654 & 1.138 & 2.404 \\
\hline Wealth & 1.166 & .338 & 11.890 & 1 & .001 & 3.209 & 1.654 & 6.227 \\
\hline Equality & .465 & .178 & 6.846 & 1 & .009 & 1.592 & 1.124 & 2.255 \\
\hline Compliance with law & .758 & .221 & 11.770 & 1 & .001 & 2.133 & 1.384 & 3.288 \\
\hline Adventure & .951 & .485 & 3.840 & 1 & .050 & 2.589 & 1.000 & 6.704 \\
\hline Creativity & .396 & .168 & 5.537 & 1 & .019 & 1.487 & 1.068 & 2.068 \\
\hline Devotion & .754 & .240 & 9.883 & 1 & .002 & 2.125 & 1.328 & 3.401 \\
\hline Public recognition & 1.094 & .256 & 18.343 & 1 & .000 & 2.987 & 1.810 & 4.929 \\
\hline Safety & .431 & .162 & 7.111 & 1 & .008 & 1.538 & 1.121 & 2.111 \\
\hline Government & .390 & .226 & 2.986 & 1 & .084 & 1.477 & .949 & 2.298 \\
\hline Church & -.274 & .167 & 2.694 & 1 & .101 & .761 & .549 & 1.055 \\
\hline Constant & -1.393 & .243 & 32.893 & 1 & .000 & .248 & & \\
\hline
\end{tabular}

${ }^{1}$ Reference category = controls. The signs in the estimates column (B) indicate the direction of the relationship, i.e. the (-) means that this variable contributes negatively. 


\section{PAPANIKOLAOU ET AL.}

Table 5.

Analysis of participants who did not trust any institution.

\begin{tabular}{|c|c|c|c|c|c|c|c|c|}
\hline \multirow{2}{*}{ Variables $^{1}$} & \multirow{2}{*}{ B } & \multirow{2}{*}{ S.E. } & \multirow{2}{*}{ Wald } & \multirow{2}{*}{ df } & \multirow{2}{*}{ Sig. } & \multirow{2}{*}{ Exp (B) } & \multicolumn{2}{|c|}{ 95\% C.I. for $\operatorname{Exp}(B)$} \\
\hline & & & & & & & Lower & Upper \\
\hline Victims of disaster & .488 & .237 & 4.225 & 1 & .040 & 1.629 & 1.023 & 2.594 \\
\hline Number of losses & & & 8.386 & 3 & .039 & & & \\
\hline No losses & -.272 & 1.447 & .035 & 1 & .851 & .762 & .045 & 12.997 \\
\hline One loss & -.819 & 1.439 & .324 & 1 & .569 & .441 & .026 & 7.401 \\
\hline Two losses & .003 & 1.472 & .000 & 1 & .998 & 1.003 & .056 & 17.976 \\
\hline Depression & .036 & .018 & 4.161 & 1 & .041 & 1.037 & 1.001 & 1.073 \\
\hline Paranoid & .021 & .012 & 2.743 & 1 & .098 & 1.021 & .996 & 1.046 \\
\hline PSDI & -.022 & .010 & 4.932 & 1 & .026 & .978 & .959 & .997 \\
\hline PST & -.061 & .020 & 9.792 & 1 & .002 & .941 & .905 & .977 \\
\hline Compliance with law & .600 & .361 & 2.756 & 1 & .097 & 1.821 & .897 & 3.697 \\
\hline Leisure & -.587 & .208 & 7.993 & 1 & .005 & .556 & .370 & .835 \\
\hline State & 1.376 & .543 & 6.413 & 1 & .011 & 3.959 & 1.365 & 11.485 \\
\hline Constant & -.792 & 1.725 & .211 & 1 & .646 & .453 & & \\
\hline
\end{tabular}

${ }^{1}$ Reference category $=$ no trust. The signs in the estimates column (B) indicate the direction of the relationship, i.e. the (-) means that this variable contributes negatively.

tutions).

Because we have found high proportions of psychological distress in both victims and controls (Papanikolaou, Adamis, Mellon, \& Prodromitis, 2011) we have hypothesized that maybe controls have been affected by the media and the distressing images which they broadcasting every day. However this explanation is less likely here. Media is difficult to rip apart the trust in all the more important organizations in so brief time (6 months after the disaster) and destroy the civic status of entire communities, despite their powerful influences. A previous study (Lyberaki \& Paraskevopoulos, 2002) has shown that Greeks have a low level of trust in the most public institutions, like political parties, the civil service, the government and the parliament. Similarly a more recent survey (Papadimitriou, 2007) in younger Greek population (18 to 28 years old) has reported that $90 \%$ did not trust the parliamentary members, $80 \%$ did not trust the trade unions, $76 \%$ did not trust the politics, and only the $38 \%$ trust the church. In addition the same survey reported that more than half (53\%) of Greek young people are unconcerned about other people and only $21.5 \%$ trust other people and those only to some degree. This survey also reveals that a $38 \%$ of young people may offer financial help in case of natural disaster to the victims.

Moreover trust has been identified as a vital component of social capital (Putnam, Leonardi, \& Nanetti, 1993). Trust in institutions is considered a central outcome measure for the identification of social capital (Newton \& Norris, 2000). Social capital has inherited difficulties to be measured because of its different operational definitions e.g. (Bourdieu, 1986; Coleman, 1988; Fukuyama, 2001; Putnam, Leonardi, \& Nanetti, 1993). However, a number of studies which measure social capital in Greece agree that Greeks have a low social capital, and the lowest when it compared with other European citizens, with any operating definition or measured outcome used, for instance, trust in institutions, social trust, social networks, social norms, voluntary participation (Christoforou, 2005; Panagiotopoulou \& Papliakou, 2007; Sotiropoulos \& Karamagioli, 2005). In addition a study which investigated social capital for 13 Greek regions found that Peloponnesus (the area where the wildfires happened) was among the last three with the lowest social capital (Jones, Malesios, Iosifides, \& Sophoulis, 2008).

Thus it is very likely that in both, cases and controls the trust and the social capital were very low before the disaster. Perhaps the concept of sociocultural "disintegration" can explain some of those findings (Leighton, 1959). According to Leighton's theory catastrophic events can disrupt norms and forms, disrupt compromised social support, and reduce the feelings of a social and moral order with consequences an increased mental health risk. Thus if we accept the Leighton's theory, a low “integrated" society is more vulnerable and has an increased risk if and when it is affected directly or indirectly by a catastrophic event. Similar observations have been reported by Dynes \& Quarantelli, 1980; Dynes, 2002; Quinn, 2006.

As our data were cross sectional we cannot be affirmed that the pre-disaster communities were already low "integrated". However given the above reported studies plus our data this is a feasible hypothesis.

In addition and in accordance with the above hypothesis, are the findings of social values and personal attitudes. Both controls and victims shared the same attitudes and values and there were not significant differences between them with few exceptions. Victims value nature more than controls (possible because they have lost it from the wildfires), they value less the public recognition and they appear more "rebellious" as they did not value the state and the compliance with law. Perhaps the last two findings is a kind of reaction to establishment as hostility and blame against society in which the disaster took place and against its leaders is common phenomenon in the aftermath of a disaster (Lopez-Ibor, 2006). However values which help the social cohesion, like dialogue and communication, stable social rules, autonomy, mutual support, equality, devotion, safety are rated quite low by both victims and controls and there were not significant differences between them. When we control for the other variables in the regression analysis (Table 4) the impact of wildfires became more profound in the community. The most important social values of a civic engagement and trust have been disappeared in the victims of the wildfires. Social norms and values like communication, mutual support, stable social rules, equality, safety, modesty, wealth, public recognition, adventure, creativity, and devotion are in a very 
low appreciation in the victims compared to controls. Thus if we accept the assumption that the controls reflect a pre-disaster level of civic status of the victims it is obvious that the disaster has destroyed even the low levels of social norms, trust and social capital.

If this model and explanations are hold and be replicated by other studies, it has serious implications for the post disaster recovery but more important for the preparation and protection of other disasters at least in Greece. Research has showed that human and social capital are essential components of resilience, and individuals and communities can effectively respond to a disaster by gather together trust, social support, and social capital to either re-establish a previous state of equilibrium or to develop a different but still adaptive state (Kirmayer, Sehdev, Whitley, Dandeneau, \& Isaac, 2009; Paton et al., 2009; Rolfe, 2006; Sakamoto \& Yamory, 2009; Schellong, 2007).

Finally we further analyzed those who did not trust any institution. Those who did not trust any institution were victims who have more losses from the disaster, more likely to be depressed and paranoid with less number of other psychological symptoms and intensity and they were more likely to value the compliance with law and the state, and less likely to value the leisure. Although a first interpretation of this finding is that they may represent an anti-social or egoistic population we need to consider two other factors, the losses and the depression. An alternative explanation is this of demoralization. Apathy is a characteristic of demoralization but is quite different from depression although those two syndromes have similar presentation. Demoralization has been defined as a state in which the individual feels helpless, hopeless, impotent, and isolated (de Figueiredo \& Frank, 1982). Demoralization is experienced as existential despair, hopelessness, helplessness, and loss of meaning and purpose in life (Clarke \& Kissane, 2002). The core symptom of demoralization is the difficulty to cope, the sense of being trapped, not knowing what to do, and coupled with social isolation the individual have the feeling of alienation (Lazarus \& Folkman, 1984). Demoralization has not yet gained its merit in psychiatric nomenclature and thus very few studies have investigated it in natural disasters although (Parson, 1990) have found symptoms of demoralization in Vietnam veterans and other individuals who have experienced a very stressful event, and he named it as Post-Traumatic Demoralization Syndrome.

Nevertheless the last finding was unexpected and not in the aims of this study and possible need further investigation and replication with new studies in natural disasters mental health outcomes.

\section{Conclusion}

In conclusion, the work presented here found that victims of the wildfires in Greece have lost their faith in important social values which bring a society together, like dialogue and communication with other people, social rules, mutual support, modesty, compliance with law, devotion, safety, and trust. In addition this study suggests that an already low level of trust in institutions, a low social capital and a weak social cohesion perhaps pre-existed the disaster and that just the disaster has made all of them worse. Thus to quote Jim Wallis "some times it takes a natural disaster to reveal a social disaster" (Wallis, 2006).

\section{REFERENCES}

Agrawal, S., Monroe, M. C., Jakes, P., Lang, E., Nelson, K., Kruger, L., \& Sturtevant, V. (2008). Exploring social foundations that support community preparedness for wildfire. Celebrating Minority Professionals in Forestry and Natural Resources Conservation: Proceedings of the Symposium on the Tenth Anniversary of the $2+2$ Joint Degree Program in Forestry and Natural Resources Conservation, 106, 55-58.

Barton, A. H. (1969). Communities in disaster; a sociological analysis of collective stress situations (1st ed.). Garden City, NY: Doubleday.

Bourdieu, P. (1986). The forms of capital. In J. G. Richardson (Ed.), Handbook of theory and research for the sociology of education (pp. 241-258). New York: Greenwood Press.

Carroll, M. S., Higgins, L. L., Cohn, P. J., \& Burchfield, J. (2006). Connnunity wildfire events as a source of social conflict. Rural Sociology, 71, 261-280. doi:10.1526/003601106777789701

Christoforou, A. (2005). On the determinants of social capital in Greece compared to countries of the European Union working paper, Fondazione Eni Enrico Mattei.

Clarke, D. M., \& Kissane, D. W. (2002). Demoralization: Its phenomenology and importance. Australian and New Zealand Journal of Psychiatry, 36, 733-742. doi:10.1046/j.1440-1614.2002.01086.x

Coleman, J. S. (1988). Social capital in the creation of human-capital. American Journal of Sociology, 94, S95-S120. doi:10.1086/228943

Crocq, L., Doutheau, C., \& Salham, M. (1987). Les reactions emotionnelles dans les catastrophes. Encyclopedie Medico-Chirurgicale. Psychiatrie (pp. 2-8). Paris: Techniques.

de Figueiredo, J. M., \& Frank, J. D. (1982). Subjective incompetence, the clinical hallmark of demoralization. Comprehensive Psychiatry, 23, 353-363. doi:10.1016/0010-440X(82)90085-2

Derogatis, L. R. (1992). SCL-90-R: Administration, scoring \& procedures manual -II, for the $R$ (revised) version and other instruments of the psychopathology rating scale series (2nd ed.). Towson, MD: Clinical Psychometric Research.

Donias, S., Karastergiou, A., \& Manos, N. (1991). Standardization of the symptom checklist 90 rating scale in a Greek population. Psychiatriki, 2, 42-48.

Dynes, R. (2002). The Importance of social capital in disaster response. Newark: Disaster Research Center, University of Delaware.

Dynes, R., \& Quarantelli, E. L. (1980). Helping behavior in large-scale disasters. In D. H. Smith, \& J. Macaulay (Eds.), Participation in social and political activities (pp. 339-354). San Francisco, CA: Jossey-Bass.

EM-DAT (2008). The OFDA/CRED International Disaster Database Prevention Web.

http://www.preventionweb.net/english/countries/statistics/index.php? cid=68 Retrieved 15/9/2010

Evans, M. D., \& Rollins, K. (2008). The fire last time: Trust, social integration, and responses to disaster management. Paper presented at the annual meeting of the Rural Sociological Society, Manchester.

Fukuyama, F. (2001). Social capital, civil society and development. Third World Quarterly, 22, 7-20. doi:10.1080/713701144

Galea, S., Tracy, M., Norris, F., \& Coffey, S. F. (2008). Financial and social circumstances and the incidence and course of PTSD in Mississippi during the first two years after Hurricane Katrina. Journal of Traumatic Stress, 21, 357-368. doi:10.1002/jts.20355

Jalali, R. (2002). Civil society and the state: Turkey after the earthquake. Disasters, 26, 120-139. doi:10.1111/1467-7717.00196

Jones, N., Malesios, C., Iosifides, T., \& Sophoulis, C. M. (2008). Social capital in Greece: Measurement and comparative perspectives. South European Society and Politics, 13, 175-193. doi:10.1080/13608740802156687

Kaniasty, K., \& Norris, F. H. (1993). A test of the social support deterioration model in the context of natural disaster. Journal of Personality and Social Psychology, 64, 395-408. doi:10.1037/0022-3514.64.3.395

Kawachi, I., \& Subramanian, S. V. (2006). Measuring and modeling the social and geographic context of trauma: A multilevel modeling approach. Journal of Traumatic Stress, 19, 195-203. doi:10.1002/jts.20108 
Kirmayer, J. L., Sehdev, M., Whitley, R., Dandeneau, F. S., \& Isaac, C. (2009). Community resilience: Models, metaphors and measures. Journal of Aboriginal Health, 5, 62-117.

Lazarus, R. S., \& Folkman, S. (1984). Stress, appraisal, and coping. New York: Springer Pub. Co.

Leighton, A. H. (1959). My name is legion; foundations for a theory of man in relation to culture. New York: Basic Books.

Lopez-Ibor, J. J. (2006). Disasters and mental health: New challenges for the psychiatric profession. World Journal of Biological Psychiatry, 7, 171-182. doi:10.1080/15622970500428735

Lyberaki, A., \& Paraskevopoulos, J. C. (2002). Social capital measurement in Greece. Paper presented at the International Conference on Social Capital Measurement.

Mellon, R. C., Papanikolau, V., \& Prodromitis, G. (2009). Locus of control and psychopathology in relation to levels of trauma and loss: Self-reports of Peloponnesian wildfire survivors. Journal of Traumatic Stress, 22, 189-196. doi:10.1002/jts.20411

Miller, L. M. (2007). Collective disaster responses to Katrina and Rita: Exploring therapeutic. Community, social capital, and social control. Southern Rural Sociology, 22, 45-63.

Montgomery, K., Jordens, C. F. C., \& Little, M. (2008). How vulnerability and trust interact during extreme events-Insights for human service agencies and organizations. Administration \& Society, 40, 621-644. doi:10.1177/0095399708321670

Newton, K., \& Norris, P. (2000). Confidence in public institutions: Faith, culture, or performance? In S. Pharr, \& R. Putnam (Eds.), Disaffected democracies: What's troubling the trilateral countries (pp. 52-73)? Princeton: Princeton University Press.

Panagiotopoulou, R., \& Papliakou, V. (2007). Facets of social capital formation in Greece. In T. Kafetzis, T. Maloutas, \& I. Tsiganou (Eds.), Politics, society and citizens: Data analysis of the European social survey (pp. 220-267). Athens: EKKE.

Papadimitriou, V. (2007). Family is a supporting system for the $60 \%$ of young people. Apogeumatini tis Kyriakis, 18-19. (Newspaper article, November 2, 2007)

Papanikolaou, V., Adamis, D., Mellon, C. R., \& Prodromitis, G. (2011). Psychological distress following wildfires disaster in a rural part of
Greece: A case-control population-based study. International Journal of Emergency Mental Health, 13.

Parson, E. R. (1990). Post-Traumatic Demoralization Syndrome (PTDS). Journal of Contemporary Psychotherapy, 20, 17-33. doi:10.1007/BF00946017

Paton, D., Houghton, B. F., Gregg, C. E., McIvor, D., Johnston, D. M., Burgelt, P., \& Horan, J. (2009). Managing Tsunami risk: Social context influences on preparedness. Journal of Pacific Rim Psychology, 3, 27-37. doi:10.1375/prp.3.1.27

Putnam, R. D., Leonardi, R., \& Nanetti, R. (1993). Making democracy work: Civic traditions in modern Italy. Princeton, NJ: Princeton University Press.

Quinn, S. C. (2006). Hurricane Katrina: A social and public health disaster. American Journal of Public Health, 96, 204. doi:10.2105/AJPH.2005.080119

Rolfe, R. E. (2006). Social cohesion and community resilience: A multidisciplinary review of literature for rural health research. Halifax: Department of International Development Studies Faculty of Graduate Studies and Research Saint Mary's University.

Sakamoto, M., \& Yamory, K. (2009). A study of life recovery and social capital regarding disaster victims-A case study of Indian Ocean Tsunami and Central Java Earthquake recovery. Journal of Natural Disaster Science, 21, 13-20.

Schellong, A. (2007). Increasing social capital for disaster response through Social Networking Services (SNS) in Japanese local governments. J. W. Goethe-University, Frankfurt am Main Harvard University.

Sotiropoulos, A. D., \& Karamagioli, E. (2005). Greek civil society: The Long road to maturity. Civicus Civil Society Index Shortened Assessment Tool Report for the Case of Greece (pp. 1-5), Athens: Access Democracy.

www.civicus.org/new/media/CSI_Greece_Executive_Summary.pdf

Turner, B. A. (1978). Man-made disasters. London: Wykeham Publications.

Wallis, J. (2006). Quoted in Quinn, S. C. Hurricane Katrina: A social and public health disaster. American Journal of Public Health, 96, 204. 